\title{
LXII. Determination of inversion temperature of Kelvin effect in hydrogen
}

\section{K. Olszewski}

To cite this article: K. Olszewski (1902) LXII. Determination of inversion temperature of Kelvin effect in hydrogen, Philosophical Magazine Series 6, 3:17, 535-540, DOI: 10.1080/14786440209462799

To link to this article: http://dx.doi.org/10.1080/14786440209462799

曲 Published online: 15 Apr 2009.

Submit your article to this journal $₫$

Џ Article views: 3

Q View related articles $\square$

Citing articles: 2 View citing articles 5 
From the above results the secular variation of declination is as follows :-

Period.
1605 to 1839
1841 " 1850
1843 " 1866
1866 " 1869
1870 " 1890
1890 " 1900

Secular Variation.

$7 \cdot 56$ increase of westerly declination.

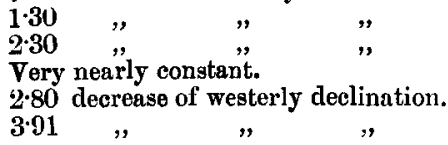

$\S 4$. The observations for intensity are fewer. The first recorded trustworthy observation was made in 1843. So far as is known to us, the results of all observations made since that date are contained in the following list. The results are given in C.G.S. units.

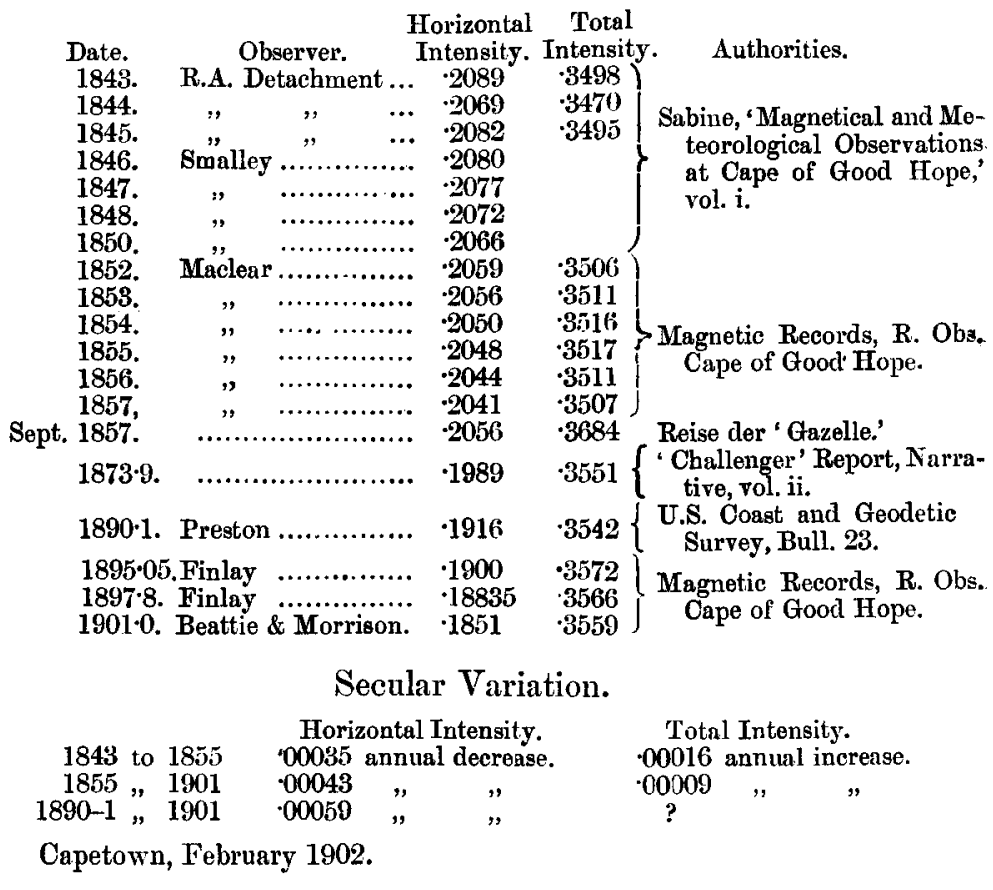

LXII. Determination of Inversion Temperature of Kelvin Effect in Hydrogen. By K. OLSZEWSKI *

TN 1854, Kelvin and Joule showed that during an irre1 versible expansion hydrogen behaves differently from all other gases:-while air in expanding from a higher to a lower pressure without the performance of external work is

* Communicated by the Author. 
cooled by an amount proportional to the difference of the two pressures, hydrogen under like circumstances becomes heated. As is well known, the Kelvin-Joule effect has been applied by Hampson and Linde to the production of liquid air on a large scale. So far as the liquefaction of hydrogen is concerned, one might have expected, in view of the peculiar behaviour of hydrogen just mentioned, that the apparatus of Hampson and Linde would not be directly applicable for this purpose; this supposition was verified by experiment. There appeared, however, to be no doubt that the apparatus of Linde, and still more so that of Hampson, could, with suitable modifications, be used for liquefying hydrogen * : it being merely a question of cooling the gas, before expansion, below the temperature corresponding to the inversion of the Kelvin effect, after which it could be liquefied by expansion.

As a matter of fact, this gas was successfully liquefied by means of apparatus constructed on the above lines first by Dewar, and then by Travers $t$. These investigators used liquid air for cooling the hydrogen, the air boiling under diminished pressure, whereby the apparatus was cooled to about $-200^{\circ}$. The question arose as to whether so strong a cooling is an indispensable condition for the liquefaction of hydrogen by means of irreversible expansion, or whether a more moderate amount of cooling would suffice.

This question could be readily answered without the necessity of undertaking a series of experiments at different temperatures, provided the temperature of inversion of the Kelvin effect were known for hydrogen.

This, however, had not been experimentally determined. Theuretically it had been deduced by Witkowski $\ddagger$ in two ways. First, by assuming the thermodynamic coincidence of the inversion temperatures for hydrogen and for air-which led to a value of about $-46^{\circ}$; secondly, by making use of an empirical formula given by Rose-Innes §. This investigator proposed the following formula for determining the cooling in the case of the Joule-Kelvin effect:

$$
e=\frac{a}{\mathrm{~T}}-\beta,
$$

* Professor Kammerling Onnes (Communications of the Leyden Laboratory, no. 23, p. 16,1896) pointed out the possibility of liquefying hydrogen in Linde's apparatus, and stated the conditions, based upon thermodynamical similarity, under which liquefaction can occur.

+ Phil. Mag. [6] i. April 1001.

$\mp$ Rozprawy of the Cracow Academy, Section of Math. and Natural Sciences, xxv. p. 247 (1898).

§ Phil. Mag. [5] xlv. p. 228 (1898). 
Inversion Temperature of Kelvin Effect in Hydrogen. 537

where $\boldsymbol{x}$ and $\beta$, calculated from the experimental data of Joule and Kelvin, amounted to $64 \cdot 1$ and 0.331 respectively for hydrogen. Assuming that there is no cooling, we obviously get by means of the above formula the temperature of inversion, which in this case amounts to $193^{\circ} .7$ on the absolute scale, i. e. to $-79^{\circ} \cdot 3 \mathrm{C}$.

In view of the considerable difference between the valnes obtained by the above two methods, an experimental determination of this temperature appeared desirable.

\section{Description of the Apparatus.}

The hydrogen used in these experiments was prepared by acting on commercial zinc with pure dilute sulphuric acid. In order to purify the gas, it was led through wash-bottles containing solutions of caustic soda and potassium permanganate, and lastly through a vessel filled with pieces of pumice-stone soaked in mercuric chloride. The gas wats collected in a large zine gasometer of 1200 litres capacity, and finally compressed, by means of a Whitehead compressor, into a steel cylinder of 13 litres capacity under a pressure of about 180 atmospheres. In the interior of this cylinder was placed a long tube constructed of wire netting and filled with sticks of caustic potash.

In preparing and compressing the hydrogen, care was taken to remove the air from all parts of the apparatus. The hydrogen could therefore be regarded as pure, in so far as it was possible, in working on a large scale, to avoid its contamination with small traces of air.

The essential part of the apparatus is shown in the figure (p. 538).

The steel cylinder containing the hydrogen under high pressure is connected, by means of a copper tube, to a metallic manometer, and also to the copper tube $a$, the continuation of which is coiled to form a worm $b$, and is closed by a valve $c$. This valve is secured to the cover $n n$ by means of an asbestospacked stuffing-box and gland $o$. By means of the handwheel $d$ the valve may be opened, when the hydrogen escapes into the box $h h$, which is made of sheet brass and stuffed with chamois leather, and expands to atmospheric pressure, escaping through the pipe pi. In the same box is contained a resistance-thermometer $e$, a full description of which is given in my paper on the determination of the critical temperature and the boiling-point of hydrogen *. The terminals $f$ and $g$ serve to connect the thermometer with the Wheatstone's

* Rozprawy of the Cracow Acadeny, xxix. p. 404 (1895); also Phil. Mag. [5] xl. p. 202 (1895). 


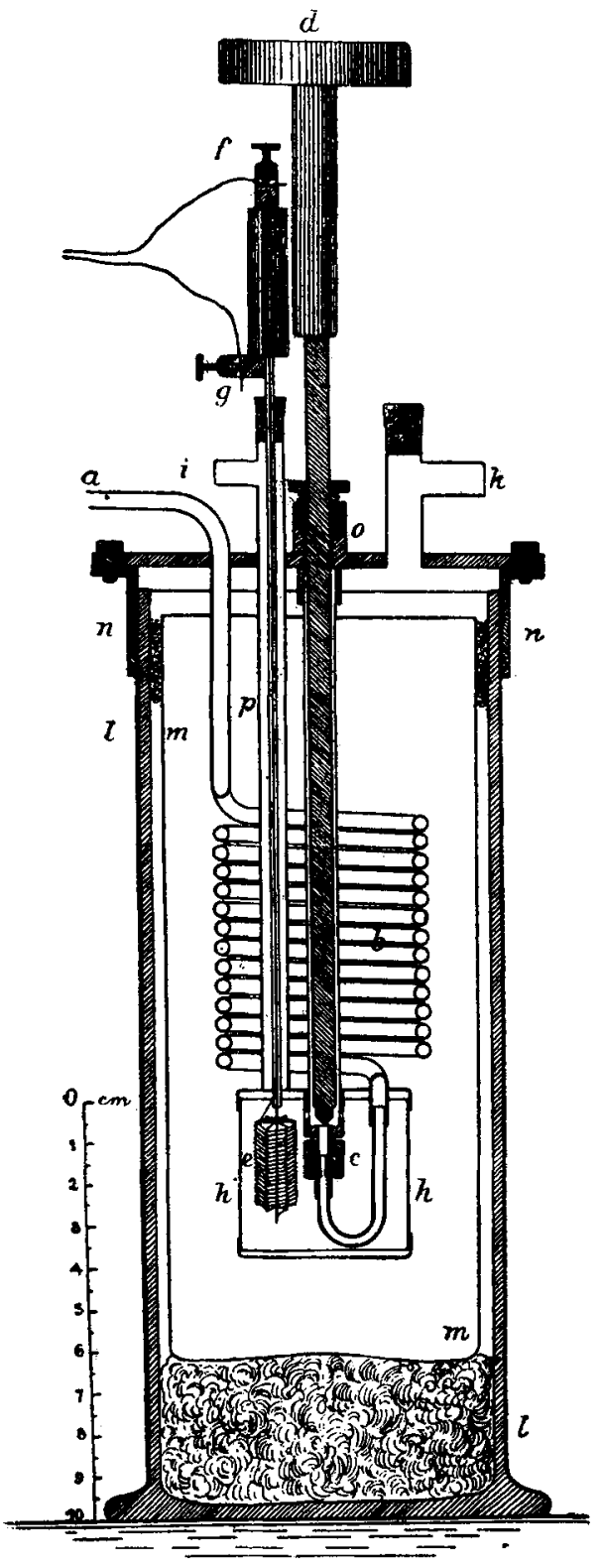


bridge. The whole of this apparatus is, by means of the metallic ring $n n$, cemented to a thick-walled glass cylinder $l l$, inside which there is a thin-walled beaker $m m$, which serves to receive the cooling agent.

Liquid air, liquid ethylene, and a mixture of solid carbonic acid and ether were used as cooling agents. The air and ethylene were poured in through the upper opening of the T-shaped pipe $k$, to a level above that of the worm $b$. The opening $k$ serves as escape-tube for the gases of the cooling substance, or-the upper opening having been closed-for connecting the interior of the apparatus with an air-pump for the purpose of lowering the pressure and temperature. In the experiments with solid carbon dioxide, this substance was introduced into the apparatus before fixing the cover $n n$. For measuring the pressure of the gases coming from the cooling substance, a mercury manometer was used, which was also in connexion with the pipe $k$, but which is not shown in the figure.

\section{Description of the Experiments.}

In the experiments with liquid air as the cooling substance, the initial temperature was about $-190^{\circ}$, and the pressure of the hydrogen before expansion about 170 atmospheres. The expansion took place slowly and lasted from 4 to 5 seconds. The cooling was considerable: the galvanometer-deflexion amounted to about $200 \mathrm{~mm}$. scale-divisions. In consequence of this, it became necessary to use a less powerful cooling agent; for this purpose liquid ethylene appeared suitable. In the experiments with this substance the initial temperature was about $-103^{\circ}$, the initial pressure about 150 atmospheres. In this case also the temperature fell during expansion, but to a much smaller extent than when liquid air was employed : the galvanometer-throw amounting to about $30 \mathrm{~mm}$ on the scale. Thus it appeared that the temperature of liquid ethylene was too low ; but for the production of higher temperatures this gas is unsuitable, hence in the third series of experiments a mixture of solid carbonic acid and ether was employed., The initial temperature was $-78^{\circ}$, the initial pressure about 117 atmospheres. In this series of experiments 25 expansions were observed, during which the pressure in the steel cylinder fell from 117 to 110 atmospheres; i.e., during a single expansion the pressure of the hydrogen was altered by about $\frac{1}{4}$ of an atmosphere, the volume of the expanded gas (measured under atmospheric pressure) amounting to about $3 \frac{1}{4}$ litres. This point is specially mentioned because in some previous experiments, not recorded here, in which the fall of pressure 
during a single expansion amounted to several atmospheres, the cooling was much stronger; in these experiments a small eylinder, of 0.6 litre capacity, which served as a reservoir for the gas to be employed during each expansion, was used in addition to the large cylinder. With such an arrangement, there is a cooling due to the performance of external work as well as a cooling due to an irreversible expansion.

At a temperature of $-78^{\circ}$ the hydrogen in expanding became slightly beated, causing a galvanometer-throw of about $3 \mathrm{~mm}$. in a direction opposed to that formerly obtained. By slow pumping and the resultant lowering of temperature, the galvanometer-throws were gradually reduced, until finally at $-80^{\circ} .5$ no deflexion was noticeable. A further lowering of temperature produced cooling, and at $-83^{\circ}$ this gave a throw of $5 \mathrm{~mm}$. in the opposite direction.

\section{Results.}

From the above experiments it follows that the temperature of inversion of the Kelvin eliect for hydrogen amounts to $-80^{\circ} \cdot 5$. This number agrees fairly well with the value deduced by Witkowski from the equation of Rose-Innes $\left(-79^{\circ} \cdot 3\right)$. This agreement between the two values makes it interesting to calculate the critical temperature of hydrogen from the assumed thermodynamic similarity of the critical temperatures of air and hydrogen, and the inversion temperature of air (deduced by Witkowski from Rose-Innes's equation). If we assume the critical temperature of air to be $133^{\mathrm{c}}$ on the absolute scale $\left(=-140^{\circ} \mathrm{C}\right.$.), the inversion tem perature of hydrogen to be $192^{\circ} \cdot 5$ absolute $\left(=-80^{\circ} \cdot 5 \mathrm{C}\right.$.), that of air $633^{\circ}$ absolute $\left(=+360^{\circ} \mathrm{C}\right.$. $)$, then we obtain for the critical temperature of hydrogen $40^{\circ} \cdot 4$ absolute, i.e. $-232^{\circ} \cdot 6 \mathrm{C}$. This temperature differs from that found by me experimentally ${ }^{*}\left(-234^{\circ} .5 \mathrm{C}\right.$.) by only $1^{\circ} \cdot 9$.

From the above experiments we may draw the conclusion that in order to liquefy hydrogen by means of the Kelvin effect, it is not absolutely necessary to cool it below $-200^{\circ}$, but that with a thermally well-insulated apparatus the temperature of about $-100^{\circ}$, which is easily obtained by using solid carbonic acid and ether, is already sufficient. There is, however, no doubt that a stronger cooling by means of liquid air helps to accelerate the liquefaction of hydrogen.

Cracow, Chemical Institute of the Jagellon University.

* Rozprauy of the Cracow Academy; also Phil. Ming. [5] xl. p. 202 (1895). 